\title{
A Leitura Deleite e suas contribuições para a Cultura do Livro
}

\author{
La Lectura Deleite y sus contribuciones a la Cultura del Libro \\ Leisure Reading and it's contributions to Book's Cuture
}

\author{
Ellem Rudijane Borba ${ }^{1}$
}

\begin{abstract}
Resumo
A Literatura se caracteriza como uma das mais completas experiências do ser humano e uma preciosa fonte de conhecimento. A leitura de textos literários favorece o contato com estético e o lúdico, estimula a imaginação e a fantasia, além de favorecer o contato com novos conhecimentos e a formação de um estreito vínculo entre ficção e realidade. Partindo da perspectiva de necessidade de uma maior aproximação entre o professor e a leitura literária, o presente artigo realiza uma reflexão sobre as contribuições da Leitura Deleite para a formação do professor leitor. Ademais, apresenta uma breve revisão de pesquisas capazes de serem relacionadas ao tema, buscando estabelecer os caminhos que os pesquisadores têm traçado para uma melhor compreensão do papel da leitura na formação docente. Entendida como um momento destinado ao prazer e fruição da leitura, com a capacidade de proporcionar a ampliação de saberes e o contato com diversos textos, o trabalho conclui sobre a importância da prática da atividade de Leitura Deleite na vida cotidiana do professor e aponta a necessidade de uma reaproximação desse profissional com a leitura literária, o que pode viabilizar um contato mais intenso entre criança e Literatura em um movimento no sentido de formá-las e torná-las leitores proficientes.
\end{abstract}

Palavras-Chave: Leitura Deleite. Formação de leitores. Leitura Literária.

\section{Resumen}

La Literatura se caracteriza como una de las más completas experiencias del ser humano y una preciosa fuente de conocimiento. La lectura de textos literarios favorece el contacto con estético y el lúdico, estimula la imaginación y la fantasía, además de favorecer el contacto con nuevos conocimientos y la formación de un estrecho vínculo entre ficción y realidad. A partir de la perspectiva de necesidad de una mayor aproximación entre el profesor y la lectura literaria, el presente artículo realiza una reflexión sobre las contribuciones de la Lectura Deleite para la formación del profesor lector. Además, presenta una breve revisión de investigaciones capaces de ser relacionadas al tema, buscando establecer los caminos que los investigadores han trazado para una mejor comprensión del papel de la lectura en la formación docente. Entendida como un momento destinado al placer y fruición de la lectura, con la capacidad de proporcionar la ampliación de saberes y el contacto con diversos textos, el trabajo concluye sobre la importancia de la práctica de la actividad de Lectura Deleite en la vida cotidiana del profesor y apunta la necesidad de una reaproximación de ese profesional con la lectura literaria, lo que puede viabilizar un contacto más intenso entre niño y Literatura en un movimiento en el sentido de formarlas y hacerlas lectores proficientes.

Palabras claves: Lectura Deleite. Formación de lectores. Lectura Literaria

\begin{abstract}
Literature has been considered one of the most complex cognitive activity that human being engages in, as well as a reliable source from which one acquires knowledge. Reading literary texts allows not only the contact with aesthetic features and ludic activities, but also it encourages the development of imagination, fantasy, provides suitable conditions for enlightenment, and the formation of the dividing line between fiction and reality. Taking the gradually growing need for approximation between teacher and literary reading as starting point, the present paper sets out to reflect on the contribution of leisure reading to the teacher-reader's formation. Furthermore, this
\end{abstract}

\footnotetext{
${ }^{1}$ Mestre em educação; UFPEL; Pelotas; Brasil; ellemsdjb@gmail.com
} 
study provides an overview of previous research on the issue. In doing so, we seek to explore the ways in which researchers have thoroughly attempted to understand the role of reading in teacher's formation. The findings from this study confirm the importance of leisure reading, which is regarded as a moment of pleasure able to extendknowledge and contact with many textsin teacher's everyday life. Besides, the results highlight the necessity of interweaving that education professional with literary reading. Consequently, these findings indicate that by merging together teacher and reading, it may be possible to establish powerful children - Literature interaction so as to turn them into proficient readers.

Keywords: Leisure reading. Reader's formation. Literary reading.

\section{Introdução}

Uma das funções sociais da Literatura é sintetizar e projetar a experiência do ser humano e do seu grupo social, atuando como veículo de expressão ou ferramenta de sua própria formação. Candido (2002), afirma que a Literatura está presente em todos os seguimentos da sociedade e se apresenta como importante veículo de manifestações culturais e artísticas, fazendo parte, de forma universal, da vida através dos tempos:

Chamarei de literatura, da maneira mais ampla possível, todas as criações e toque poético, ficcional ou dramático em todos os níveis de uma sociedade, em todos os tipos de cultura, desde o que chamamos folclore, lenda, chiste, até as formas mais complexas e difíceis da produção escrita das grandes civilizações. (CANDIDO, 2002, p. 174)

Segundo Rosa (2017), “a obra literária não tem a tarefa de informar, embora possa fazer isso, não tem a tarefa de educar, apesar de poder. Tem compromisso com a emoção, a imaginação e a estética”. Esse compromisso permite à obra literária um caráter libertário e faz com que ultrapasse questões didáticas e pedagógicas para favorecer a construção de conhecimentos e experiências não apenas de forma consciente, mas também de forma inconsciente, já que é capaz de atuar no subconsciente do leitor, conferindo-lhe poder educativo similar à educação familiar ou escolar. A literatura, portanto, transmite uma espécie de conhecimento que de maneira indireta se transforma em aprendizado e de modo inconsciente satisfaz a necessidade de entender a complexidade dos sentimentos humanos e a sociedade em que se vive.

Duarte Júnior (2000), considera que a arte "educa" em uma dimensão não racional, refinando as percepções e a sensibilidade do ser humano. Assim, uma maior aproximação entre arte e educação possibilitaria ao ser humano experiências sensíveis e vivências que não estão presentes no seu cotidiano, oferecendo acesso ao simbólico e ficcional de outros universos e outras realidades. Ao assegurar a experiência estética como fundamental para a formação humana, o autor vislumbra a ficção e a imaginação como possibilidades para a 
ampliação do saber sensível, possibilitando o alcance a conhecimentos e saberes mais abrangentes para a educação. Assim, buscando-se uma melhor compreensão da ligação entre imaginação e realidade, em decorrência das práticas de leitura caracterizadas pelo prazer e refletindo sobre a importância da formação do professor leitor, a Leitura Deleite - entendida como um momento destinado ao prazer e fruição da leitura e que tem a capacidade de proporcionar a ampliação de saberes e o contato com diversos textos - surge como o tema principal deste trabalho.

Dessa forma, a partir da perspectiva de uma maior aproximação entre o professor e a leitura literária, o presente artigo realiza uma reflexão sobre as contribuições da Leitura Deleite na formação do professor leitor, apresentado uma breve revisão de pesquisas sobre o tema. Este trabalho emerge de um projeto de pesquisa maior em desenvolvimento, cujo objetivo volta-se à análise de possíveis modificações nas práticas de leitura pessoal dos professores alfabetizadores em decorrência das atividades de Leitura Deleite, realizadas nos Cursos de Formação de Professores do PNAIC - Pacto Nacional pela Alfabetização na Idade Certa (BRASIL,2012). O interesse neste tema deve-se ao papel altamente significativo dos professores na promoção e orientação da leitura, o que envolve o constante desenvolvimento de sua condição de leitor, principalmente a partir da vivência cotidiana dessa prática. Portanto, o investimento em uma formação leitora para os professores potencializaria a formação de leitores e o alcance de melhorias nos índices de alfabetização.

Este artigo encontra-se dividido em três partes. A primeira reflete sobre as práticas de leitura e as funções que a Literatura desempenha na formação humana. A segunda considera a necessidade de maior aproximação entre os docentes e a atividade de leitura por prazer e fruição, visto que formar o aluno leitor também envolveria o investimento na formação do professor leitor. A terceira apresenta alguns trabalhos abrangendo a formação do professor leitor e a Leitura Deleite, como forma de vislumbrar o caminho que os pesquisadores têm percorrido sobre o tema. Ao final, as articulações das ideias desenvolvidas nesses itens constroem as conclusões da pesquisadora frente ao objetivo deste trabalho.

\section{A leitura na formação humana: pressupostos da Leitura Deleite}

O conceito de Leitura Deleite adotado no presente trabalho não se restringe apenas às atividades de leitura desenvolvidas em sala de aula, como as leituras realizadas pelo professor com suas crianças, mas a todas aquelas práticas de leitura que envolvem o ler pelo prazer, fruição e sobretudo deleite, motivo pelo qual deveriam romper os muros da escola e estar presentes de forma constante no cotidiano estudantes e professores. Ao caracterizar esse tipo 
de leitura, Alves (2005) afirma que as coisas do mundo se dividem em duas ordens, a ordem do "utili" e a ordem do "frui". O autor usa a metáfora da caixa de coisas inúteis, que seria sustentada pela:

[...] mão esquerda, a mão do coração. Essa caixa está cheia de coisas que não servem para nada. Inúteis. Lá estão um livro de poemas de Cecília Meireles, a "Valsinha" do Chico, um cheiro de jasmim, um vento no rosto, uma sonata de Mozart, o riso de uma criança, um saco de bolas de gude [...] (ALVES, 2005, p.12)

Valendo-se da imagem mental de um corpo, que na mão direita carrega uma caixa de ferramentas e na esquerda uma caixa de brinquedos, o autor discorre sobre os saberes que o ser humano precisa desenvolver no transcorrer de sua vida. Entre esses saberes está a utilização das "ferramentas", objetos da ordem do "útil”, que o homem precisa lançar mão para sobreviver e se adaptar ao mundo que o cerca. A Leitura Deleite poderia se encontrar na caixa da mão esquerda, na caixa de brinquedos, na qual estão os objetos da ordem, da fruição, do prazer. "Coisas inúteis" e por isso mesmo imprescindíveis na vida do homem, visto serem portadoras de amor e de alegria com base no deleite. Contudo, o livro também se apresenta como objeto de saber, por isso pode-se pensar nele como pertencente à caixa de ferramentas, já que é portador de conhecimentos adquiridos pela humanidade através dos tempos, portanto, pertencente à ordem dos objetos úteis. Desse modo a leitura além facilitar o acesso ao prazer e à emoção tem a capacidade de atuar como objeto de ensino, o que torna essas dimensões complementares na vida do ser humano.

Investir na formação leitora do professor envolve atuar na mediação da leitura no ambiente escolar, já que o mediador constrói uma ponte entre o autor e o público, apresentando os autores e suas palavras com o objetivo de despertar a sensibilidade para o qual aquela construção poética foi pensada. Essa ideia de construção poética se refere a "[...] uma colocação específica da consciência, pela qual os objetos são apreendidos de outro modo que não o corriqueiro. Tal consciência revela a dimensão poética, ou estética, das coisas ao redor" (DUARTE JÚNIOR, 2010, p. 73). Contudo, nem toda a construção poética resulta neste formato, podendo aparecer em outras formas como quadros, música, obras de arte, ou até mesmo, em textos na forma de prosa, ou seja, a construção poética depende do olhar poético do autor sobre o mundo e da percepção do leitor. Importante ressaltar aqui que os processos de construção e recepção dos textos não ocorrem de forma linear, envolvem elementos conscientes e inconscientes do artista e do leitor, que muitas vezes escapam à linearidade e à classificação, já que criação trabalha em um campo não convencional, sendo que o impacto da produção artística geralmente não pode ser controlada. 
A leitura literária, por ser uma experiência estética que envolve o intelecto e a cognição, mobiliza sensações, percepções, consciência e reflexão, dessa forma, a leitura literária necessita das conexões de sentidos, ou seja, conexões estéticas que possibilitem o despertar das emoções estéticas presentes naquela obra. O leitor apreende os sentidos oferecidos pela leitura por meio da visão, travando um primeiro contato com o produto gráfico livro ou mesmo em outros formatos como, por exemplo, os e-books ${ }^{2}$. O público, pela sonoridade da leitura tem a possibilidade de, mediante a audição, apreciar a beleza daquela construção. Todas as palavras grafadas no texto foram pensadas, cuidadosa e estrategicamente para despertar determinadas emoções e sentimentos no leitor. Portanto a mediação só se dá através da leitura do texto por inteiro, ou seja, o encontro entre a obra e público só ocorre se o mediador tiver em mente quais emoções podem ser despertadas a partir da sonoridade proporcionada pela leitura do texto. Dessa forma, o ato de mediação da leitura também significa um ato de elaboração da sensibilidade.

Duarte Júnior (2010) aponta dois modos de relacionamento do homem com o mundo: percepção prática e percepção estética. Na percepção prática, os objetos são considerados pela sua utilidade, ou pela sua funcionalidade, tendo a linguagem para condicionar, enquadrar e classificar esses objetos. Esse modo prático de relação possibilita ao homem a sobrevivência e a construção de instrumentos que servem para facilitar sua vida. Esses instrumentos podem ser materiais, como as ferramentas ou equipamentos diversos ou simbólicos como as teorias ou a linguagem.

Para a percepção estética, ao contrário, a função dos objetos não é importante, mas sim sua forma e o modo como ela é percebida e simbolizada pelo homem. Essas formas atuam de maneira subjetiva no ser humano e podem espelhar e revelar as emoções e os sentimentos de acordo com as particularidades únicas despertadas por esses objetos e por sua relação com a memória individual a eles relacionada. Duarte Júnior $(2000 ; 2010)$ reflete sobre o quanto uma maior aproximação entre a sensibilidade e o intelecto, ou entre a percepção estética e a percepção prática poderiam contribuir para a educação.

\footnotetext{
De pronto e ao longo da vida aprenderemos sempre com o "mundo vivido", através de nossa sensibilidade e nossa percepção, que permitem nos alimentemos dessas espantosas qualidades do real que nos cerca: sons, cores, sabores, texturas e odores, numa miríade de impressões que o corpo ordena, na construção do sentido primeiro. $\mathrm{O}$ mundo, antes de ser tomado como matéria inteligível, surge a nós como objeto sensível. (DUARTE JÚNIOR, 2000, p.15).
}

\footnotetext{
${ }^{2}$ E-books, livros digitais, ou até mesmo livros eletrônicos, são termos cunhados que representam um mesmo objeto, sendo considerados livros independente do suporte e gênero. (RIBEIRO, 2013, p. 05).
} 
Para o autor, o saber sensível se relaciona com diversos conhecimentos do ser humano, desde o saber corporal aos processos mais complexos como raciocínio e reflexão, sendo o tipo de saber que serve de possibilidade para todos os outros conhecimentos, entre eles o educacional. Desse modo, o mundo se apresenta antes de mais nada como objeto sensível, não podendo ser compreendido somente com a inteligência e o raciocínio.

Paulino (2014, p. 177) se refere à leitura literária como uma prática cultural e artística capaz de proporcionar ao leitor uma sensação de prazer, estabelecendo um pacto entre leitor e texto em uma dimensão imaginária através do contato com outros universos e emoções "em que nascem seres diversos, com suas ações, pensamentos, emoções", favorecendo assim, a dimensão imaginária do ato de ler. Logo, a leitura literária tem a possibilidade de proporcionar a experiência mais completa da leitura. A fantasia presente na obra literária quase nunca é pura, pois e se refere invariavelmente a determinada realidade inerente à sociedade em que ela está inserida, dessa forma, a imaginação e a realidade possuem uma estreita ligação.

Paiva, Maciel e Cosson (2010, p. 32), concordam com a validade do texto literário como o mais adequado para o desenvolvimento da atividade de Leitura Deleite, já que a Literatura é um poderoso instrumento educacional podendo ser utilizada nos currículos escolares como equipamento intelectual e afetivo, o que favorece redescobrir sentimentos, emoções e visões de mundo.

\footnotetext{
Os gêneros literários talvez sejam dos mais significativos para a formação de um acervo cultural consistente. De um lado, como os textos literários costumam propositadamente trabalhar com imagens que falam à imaginação criadora, muitas vezes escondidas nas entrelinhas ou nos jogos de palavras, apresentam o potencial de levar o sujeito a produzir uma forma qualitativamente diferenciada de penetrar na realidade. De outro, podem provocar no leitor a capacidade de experimentar algumas sensações pouco comuns em sua vida [...]. (PAIVA, MACIEL E COSSON, 2010, p. 32)
}

Candido (2002) sustenta que uma das funções sociais da Literatura consiste na capacidade de confirmar a humanidade do homem, assim, a obra literária mostra-se como objeto de conhecimento além de ser capaz de sintetizar e projetar a experiência do homem não só de forma individual, mas, considerando o grupo social em que está inserido. Dessa forma, a Literatura constitui veículo da expressão do homem e também ferramenta para sua própria formação. A função humanizadora da Literatura transparece principalmente na construção da obra, na organização das palavras, no ritmo e na forma como o conteúdo literário é apresentado, essa função faz com que se estabeleça conexão com os sentimentos do leitor e permite ao conteúdo adquirir forma e significado e atuar nas capacidades de ver e sentir do ser 
humano.

Portando, conclui-se que a leitura possui poder formativo e se apresenta como parte integrante do capital cultural humano, o que a torna capaz de possibilitar formas de educação ampliadas, possíveis de transcender a função escolar. A Literatura “[...] é fator indispensável de humanização e, sendo assim, confirma o homem na sua humanidade" (CANDIDO, 2002), condição que a torna direito fundamental do ser humano, visto ser o sonho e a fantasia inerentes à essência humana. Além disso, a Leitura Deleite, por ser uma manifestação artística, atua na percepção estética e possibilita aproximação entre o intelecto e a sensibilidade, favorecendo construção de conhecimentos e experiências em todos os contextos da vida, logo, essa atividade não precisa se condicionar ao espaço escolar, podendo se tornar presença constante no cotidiano não só dos alunos, como também dos professores.

\section{3 . A Leitura Deleite na formação do professor leitor}

O ler pelo prazer de ler está se tornando uma opção didática consideravelmente produtiva nas salas de aula. Segundo o material trabalhado no PNAIC, a Leitura Deleite se caracteriza por ser um momento destinado ao:

[...] prazer e reflexão sobre o que é lido, sem se preocupar com a questão formal da leitura. É ler para se divertir, sentir prazer, para refletir sobre a vida. Tal prática, no entanto, não exclui as situações em que se conversa sobre os textos, pois esse momento também é de prazer, além de ser de ampliação de saberes (BRASIL, 2012, p. 29).

Portanto, essa atividade objetiva estimular o gosto pela leitura e refletir sobre as diversas funções que ocupa na vida social do indivíduo. A Leitura Deleite deve possibilitar o contato com diversos textos e favorecer o alcance de novos conhecimentos, além de estimular a criatividade e promover a imaginação e a fantasia, assim como estabelecer uma nova aproximação entre leitor e texto através da valorização do prazer e da fruição do ato de ler.

Ao abordarem a mediação do professor nos processos de leitura literária, Paiva, Maciel e Cosson (2010), veem a importância de propor a fantasia e estimular a imaginação da criança, para isso, faz-se necessário a oferta de textos de boa qualidade, capazes de favorecer um olhar para a diversidade de linguagens que integram o mundo. A preocupação docente não deveria se restringir ao que ensinar, mas considerar a experiência de leitura em todas as suas dimensões sensoriais, entre elas o tato, relacionado ao prazer com manuseio dos livros, que envolve as texturas do papel, as ilustrações, o planejamento gráfico. O professor precisa ler a obra como um leitor comum, deixar-se envolver espontaneamente pelo texto, sem outro 
objetivo além do prazer e a fruição.

Outro fator importante que interfere diretamente na tarefa de mediação leitora do professor diz respeito a problemas na sua história de leitura e qualificação profissional. Esse fato faz com que muitos professores não se interessem por ler ou contar histórias para seus alunos. Dentre os motivos para esse pouco envolvimento com a leitura está o pouco contato com os livros durante a infância ou em consequência de uma qualificação docente incapaz de aproximar ou reaproximar o professor com a Literatura. Essa aproximação torna-se fundamental para um maior contato das crianças com as obras literárias, e para o alcance do objetivo de formá-las e torná-las leitoras proficientes.

\begin{abstract}
Ser mediador da leitura é conseguir compartilhar com a criança. Quando o professor é um entusiasta da leitura e comunica esse entusiasmo às crianças, existe grande possibilidade de que estas sejam seduzidas pela leitura, por conta da curiosidade sobre o que está sendo lido. É muito importante que a criança veja o professor lendo. Nos momentos em que as crianças leem silenciosamente, é interessante que o professor o faça também, de modo que o ambiente escolar seja visto como lugar agradável do exercício da leitura para ambos (PAIVA; MACIEL; COSSON, 2010, p. 51).
\end{abstract}

Segundo os Parâmetros Curriculares Nacionais (PCN) de Língua Portuguesa (BRASIL, 1997, p. 43), a “leitura, como prática social, é sempre um meio, nunca um fim. Ler é resposta a um objetivo, uma necessidade pessoal". Desse modo, a leitura se apresenta como uma ferramenta potencial para a aprendizagem e para uma educação de qualidade e contribui para o desenvolvimento social, cultural e intelectual do leitor. A prática da leitura viabiliza o acesso ao conhecimento e à cultura oferecendo possibilidade de colaborar para o desenvolvimento do intelecto, assim como, estimular o raciocínio e melhorar o vocabulário. De acordo com Zilberman (1993), essa atividade repercute de forma positiva na fala e na escrita do aluno, além de melhorar seu domínio cognitivo e mobilizar nas suas emoções e preferências.

A escola por ser um ambiente propício ao desenvolvimento e às transformações sociais e culturais, tem como um de seus maiores desafios melhorar os índices para a formação de leitores, visto ser essa atividade fundamental para o acesso a um conjunto de conhecimentos socialmente elaborados e necessários para o exercício da cidadania. Dessa forma, o ambiente escolar se apresenta como um dos principais espaços aptos a aproximar os estudantes brasileiros dos textos escritos. Embora a leitura se caracterize como uma atividade não apenas escolar, mas social, inevitavelmente, muitos são os modelos de produção escrita capazes de contribuir para o letramento dos jovens e crianças, a autora acredita que privilegiar a leitura literária representa uma excelente alternativa para transcender a função escolar da 
leitura, além de possibilitar o alcance de um dos principais objetivos da educação, que é inserir o aluno nessa prática social.

[...] a obra de ficção, fundada na noção de representação da realidade, exerce tal papel sintético de forma mais acabada, fazendo com que leitura e literatura constituam uma unidade que mimetiza os contatos materiais do ser humano com seu contorno físico, social e histórico, propondo-se mesmo a substituí-los (ZILBERMAN, 2009, p. 32-33).

A Leitura Deleite, entendida como aquela feita exclusivamente por prazer, diferenciase de outros tipos de leitura que permeiam a vida em sociedade, principalmente a dos professores, por ser a leitura uma importante ferramenta de trabalho que lhes possibilita ampliar e qualificar suas práticas, além de facilitar a descoberta de outros modos de resolução de problemas, fornecendo ferramentas adequadas para lidar com os problemas que encontram para "sobreviver na profissão"3.

A profissão docente exige certo número de saberes particulares que servem de base para a sua prática. Este repertório de saberes, próprio da profissão, não deve ser separado do conjunto de saberes que o professor, enquanto indivíduo possui, eles são inerentes a sua experiência de vida pessoal e são denominados saberes "culturais e pessoais". Gauthier (1998) salienta que a distinção entre saberes docentes e "saberes e pessoais" é bastante abstrata, porém permite que a pesquisa sobre os saberes docentes não se perca na imensidão dos saberes possuído por cada indivíduo, visto que diversos saberes podem ser mobilizados para fins específicos ao ensino e podem ser utilizados em sala de aula. A leitura literária, por exemplo, se caracteriza como um tipo de saber específico de quem tem esse tipo de leitura presente em seu cotidiano. Esses saberes podem ser colocados em prática nas atividades de leitura que o professor venha a realizar na sala de aula com as suas crianças. Nóvoa (1995), considera a importância de investimento na elaboração de um conhecimento pessoal inserido em um conhecimento profissional, capaz de ultrapassar as dimensões técnicas ou científicas da profissão. $\mathrm{O}$ autor reforça que os cursos de formação de professores deveriam dedicar uma atenção especial às dimensões pessoais da profissão docente: “[...] ensinamos aquilo que somos e que naquilo que, somos, se encontra muito daquilo que ensinamos [...]" (NÓVOA, 2009, p. 212), o que reforça a necessidade de um trabalho sobre si, através da autorreflexão e da autoanálise.

Assim, com o objetivo de refletir sobre as concepções de leitura presentes nos

\footnotetext{
${ }^{3}$ Tardif (2012), sistematiza a noção de Saberes Práticos de Sobrevivência a partir da junção dos conceitos de saberes e das diversas abordagens que os professores se utilizam para tentar resolver as adversidades que surgem no transcorrer do ofício docente.
} 
trabalhos com os textos, os contextos de produção e sobre a mediação da escola e do professor no processo de formação de leitores, faz-se necessário que a principal recomendação para que o ensino da leitura em sala de aula seja produtivo que o professor seja um bom leitor, além gostar de ler e ter a leitura presente em seu cotidiano, o que torna conveniente compreender como as práticas de leitura por deleite se fazem presentes na vida pessoal do professor e na formação.

Logo, pode-se considerar que o objetivo da presença de um momento permanente para os professores desfrutarem do ler por prazer em um curso de formação continuada, como ocorria, de maneira permanente, na dinâmica dos encontros do PNAIC, teria o propósito de proporcionar uma reaproximação entre estes e a leitura, além de uma tentativa para recuperar o prazer e o hábito da leitura que por um motivo ou outro, esses professores tenham perdido com o passar do tempo:

A formação não se constrói por acumulação de cursos, conhecimentos ou técnicas, mas sim através de um trabalho de reflexividade crítica sobre as práticas e de (re)construção permanente de uma identidade pessoal. Por isso é tão importante investir na pessoa e dar um estatuto de saber a experiência (NÓVOA, 1992, p. 25).

Para encerrar essa reflexão é importante salientar que uma nova corrente de estudiosos da educação, entre eles Nóvoa (1992, 1995), Tardif (2012), Roldão (2007), Gauthier (1998), Pimenta (2012) entre outros, reconhecem que não é possível construir uma pedagogia que ignore a dimensão pessoal e profissional do trabalho docente. Dessa forma as técnicas ou os conhecimentos utilizados em sala de aula não são tão importantes quanto a forma como cada um vive a profissão. Portanto, identidade profissional se constrói a partir do equilíbrio entre as características pessoais e a trajetória profissional do professor, logo, é possível pensar a formação de professores em um amplo sentido, capaz de envolver a sensibilidade, emoção, as ligações afetivas, o que valida a presença dos saberes literários entre os conhecimentos docentes.

Assim, a prática da Leitura Deleite se apresenta como uma forma produtiva de investir não apenas na qualificação do professor como mediador da leitura, mas como leitor e também na sua formação pessoal, sensível e estética, contribuindo assim, para a uma maior valorização da identidade desse profissional através da valorização de seus saberes pessoais. Com o objetivo de corroborar com outros estudos sobre a Leitura Deleite e sobre as práticas de leitura em geral, assim como refletir quais os caminhos trilhados pelos pesquisadores que estudam formação de leitores, realizou-se uma revisão de literatura com o foco em pesquisas realizadas sobre a temática deste trabalho, cujos resultados são expostos a seguir. 


\section{Pesquisas sobre a Leitura Deleite e formação do professor leitor}

De acordo com os resultados da pesquisa "Retratos da Leitura no Brasil 4" (FAILLA, 2016), observa-se um crescimento da população leitora no Brasil. Contudo, o acesso à leitura não está ao alcance de todos os brasileiros, nem mesmo o ingresso à escola garante a competência leitora de maneira uniforme a toda a população brasileira, resultando na importância de uma visão mais aprofundada sobre formação de leitores no ambiente escolar e sobre a formação do professor leitor. Para tanto, foi realizada uma revisão de literatura em meados de 2016 que, inicialmente, envolveu a busca do descritor "Leitura Deleite", em três sítios eletrônicos, Biblioteca Digital Brasileira de Teses e Dissertações, SciELO - Scientific Electronic Library Online e Banco de Teses e Dissertações da Capes, sendo que apenas no último foi obtido duas ocorrências, ambas relacionadas com os cursos de formação de professores do PNAIC. Passou-se, então, ao uso do descritor "professor leitor", resultando em 32 trabalhos no site da Biblioteca Digital Brasileira de Teses e Dissertações e 68 no Banco de Teses e Dissertações da Capes. Após a análise desses, foram priorizados aqueles que mais se relacionavam com os temas abrangidos neste trabalho (Leitura Deleite; Leitura Literária e Formação do Professor Leitor), totalizando doze trabalhos apresentados a seguir.

Ao analisar como os professores alfabetizadores se expressam sobre suas práticas e saberes docentes após a formação continuada do PNAIC em 2013, Lovato (2016) conclui que para as participantes da pesquisa a atividade de Leitura Deleite realizada em sala de aula despertou o interesse das crianças pela leitura, principalmente a leitura literária, já que os discentes têm acesso as obras na sala de aula, que podem ser lidas tanto por eles, como pelas professoras alfabetizadoras. A pesquisa também aponta avanços e suscita questionamentos sobre a importância da formação de professores, visto que estes não são meros executores de teorias, mas agentes ativos no processo de ensino, o que demanda o abandono de práticas prescritivas e propostas prontas sobre o fazer docente.

Bastos (2016) analisou as práticas pedagógicas de professoras do ciclo de alfabetização que participaram dos encontros de formação do PNAIC com o objetivo de averiguar a utilização dos acervos de livros do Programa Nacional do Livro Didático (PNLD) e da coleção de Obras Complementares e de Alfabetização na Idade Certa, disponibilizada para a formação de uma pequena biblioteca nas salas de aula das turmas de alfabetização. A pesquisa revelou, que depois de participarem dos cursos de formação do PNAIC, as alfabetizadoras apontaram mudanças em suas práticas, pois se apropriaram de estratégias pedagógicas sugeridas pelo Programa, o que refletiu na interação das crianças com os 
diversos gêneros textuais, tanto dos acervos do PNLD, como de outros acervos pessoais das professoras e da escola, por meio da Leitura Deleite, sequência didática e como propósito para produção de texto.

Caldeira (2008) traçou um perfil do professor leitor de poesia, tomando como base seu histórico de vida cultural e profissional. Conforme apurado na pesquisa, o que caracteriza um comportamento leitor é o fato de que apesar do pouco tempo disponível para o lazer, o professor leitor consegue dispor de algumas horas por dia para realizar suas práticas de leitura, esses horários geralmente são após o almoço, ou antes, de dormir. Além disso, através de respostas ao questionário utilizado na pesquisa, é possível perceber os diferentes modos de envolvimento com a leitura, ficou comprovado que o professor assume dois papéis: o de mediador da leitura e o leitor propriamente dito. Quanto à mediação de leitura, exige-se do professor a emissão de juízo sobre as obras lidas, com o objetivo de vincular obra e receptor, nesse caso os alunos. Mas antes disso, o professor assume o papel de leitor, visto ser este o fundamento para que se tornar apto a exercer qualquer mediação.

O trabalho de Morais (2014) analisou as características pessoais e sociais das leituras de professores de Pedagogia da uma rede privada de ensino, considerando as trajetórias de formação como leitores e suas práticas docentes. A pesquisa envolveu a formação de docentes que atuam no Ensino Superior em uma dimensão importante e algumas vezes negligenciada, que diz respeito às práticas de leitura desses docentes:

[...] o que leem, em que suas leituras interferem ou não em sala de aula? O que esses professores fazem nas horas em que estão fora da sala de aula? Qual o lugar que ocupa a leitura em sua vida particular e nas práticas docentes? As leituras que esses professores desenvolvem trazem consequências em sua interação direta com os alunos, intervindo na apropriação que os discentes fazem dos conteúdos? Como a leitura é concebida e planejada pelos professores na graduação? (MORAIS, 2014, p. 27).

Portanto, o professor leitor atua como facilitador da leitura, sendo que sua paixão pelo ato de ler representa um papel importante no processo de formação do aluno leitor. Desse modo, a figura do professor leitor se opõe ao discurso positivista, que prioriza a leitura utilitária, a leitura que se condiciona apenas à obtenção de conhecimento e informação, em lugar da leitura que prioriza a formação humana por ser permeada de elementos lúdicos e de fruição estética capaz de desenvolver nos alunos uma formação harmoniosa, equilibrada em seus aspectos cognitivos e afetivos, ou seja conectando razão e sentimento.

Em sua pesquisa "Histórias de leitura: A formação do professor leitor", Tardelli (1997) buscou uma melhor compreensão da relação entre a concepção canônica de leitura e 
outras formas e representações do ato de ler. Uma das questões abordadas foi em relação à posição assumida pelas professoras ao ingressarem em seus estudos, enquanto objetos de pressão do cânone literário e posteriormente ao começarem a lecionar, como agentes e sujeitos de pressão desse mesmo cânone, no cumprimento das exigências de legitimação da leitura de seus alunos. No caso dos professores de Língua Portuguesa, a leitura literária é uma das especificidades dessa função, portanto passa a assumir uma função não só de fruição, prazer e deleite, mas também como exigência para o bom desempenho dessas docentes. Contudo é possível perceber que as professoras entrevistadas conseguem manter paixões por textos que não pertencem somente ao Cânone Literário, como o caso de uma das entrevistadas que coloca a leitura de revistas-livros de Mangá ${ }^{4}$ como a leitura que faz por prazer, porque gosta, segundo ela essas leituras saem de seu contexto de trabalho e tornam-se fonte de prazer e fruição, ou seja, são suas leituras deleite.

Em trabalho posterior, Tardelli (2003) objetivou observar e compreender os processos de construção de sentido operados em um grupo específico de leitores (professores de língua portuguesa) diante dos diferentes textos que compõem a sua trajetória de leitura e de que forma esses leitores lidam com as possíveis contradições advindas da relação entre a diversidade de leituras presentes no processo de formação de professores e as influencias que essas leituras exercem na imagem do professor, como legitimador da leitura canônica perante a escola e a sociedade. Segundo a pesquisa, a "crise de leitura" enfrentada no Brasil é mais um dos problemas sociais vivenciados desde os tempos em que éramos colônia de Portugal, além disso, a situação tende a se agravar pela falta de uma política educacional adequada e uma rede escolar eficiente. Contudo, a pesquisa também mostra que imagem estereotipada do professor não-leitor não corresponde à realidade desses profissionais, já que existe a presença de uma prática de leitura social e coletiva comprova a existência do professor-leitor.

Asbahr (2005) refletiu sobre prática do professor-leitor que trabalha com os livros de autoajuda para crianças em sala de aula, a autora reconhece que a preferência por essas obras, além de revelar as leituras que essas professoras elegem para seu deleite, reflete a uma forma de ler própria de um momento histórico e que não se restringe apenas a essa categoria, mas às práticas de leitura presentes em uma sociedade. As professoras leitoras de livros de autoajuda leem obedecendo alguns condicionamentos, no espaço escolar com a finalidade profissional, porém fora desse espaço, a leitura é movida por outras intenções, o que possibilita vários

\footnotetext{
${ }^{4}$ Mangás são histórias em quadrinhos japonesas e sua leitura é feita de trás para frente. Informações retiradas do site: http://brasilescola.uol.com.br/artes/o-que-e-manga.htm.
} 
questionamentos: “qual é a concepção de conhecimento nesse contexto? Que leitura é essa? Que criações são feitas a partir das leituras realizadas?".

A pesquisa de Ramalho (2006) aponta para a necessidade da ampliação dos conceitos de leitura e para a constituição de um olhar que contemple as diferentes práticas de leitura e para a participação da escola, assim como da comunidade e da família na tarefa de formar leitores. O trabalho foi desenvolvido em um curso de formação de professores no qual a autora atuou como coordenadora e, a partir da constatação de dificuldades apresentadas pelas professoras cursistas em realizar as práticas de leitura exigidas pelo curso, foram apresentados vários questionamentos, entre eles o seguinte: "Professor não leitor forma leitores?". Outra questão levantada nessa pesquisa se refere à base de constituição de leitores, que deve ser construída a partir de um primeiro contato prazeroso com a leitura, valorizando a leitura espontânea e o contato com os mais diversos portadores de textos em ambientes informais, sem intenções didáticas e pedagógicas, esse contato inicial da criança seria fundamental para despertar o gosto e paralelamente a formação do hábito da leitura.

Silva (2007), ao analisar a importância da construção de sentidos na formação do professor leitor, interroga sobre o tipo de formação que deve ter o professor egresso do Curso de Letras para trabalhar com o novo Livro Didático e suas múltiplas linguagens. O autor considera que para o ensino da leitura o professor precisa ler compreendendo a leitura em seus níveis mais profundos, somente assim, estará apto para ensinar a ler lendo, ou seja, volta-se ao tema de que o para o professor possa ensinar a leitura precisa, em primeiro lugar, ser leitor. Entre as competências exigidas desse professor está a presença de um repertório de conhecimentos e habilidades linguísticas-semióticas adquiridos na graduação e em outras fases de sua vida, pela prática da leitura.

Aragão (2014) investigou a relação entre professor leitor e as atividades de leitura na infância ou juventude e após assumir a docência. Uma das conclusões da autora é que as práticas de leitura dos professores investigados remontam de uma aprendizagem no âmbito familiar e escolar, além disso, os professores possuem uma trajetória de leituras adquirida ao longo de sua vida, na formação inicial e durante sua atuação profissional. Outro ponto apurado na pesquisa aponta que as práticas de leitura exigem uma polissemia de sentidos, sendo que cada tipo de leitura apresenta pré-requisitos que determinam sua função: leituras teóricas se direcionam a formação e aprendizado, enquanto que a leitura de textos literários, por deleite torna a leitura lúdica e prazerosa. Existe também a leitura de obras de Literatura indicadas para o trabalho com os alunos, essa leitura é voltada para o ensino, portanto, a função determina os modos e gestos da leitura. 
Finalmente, segundo Silva (2015), a formação de leitores adultos requer leituras cujas problemáticas tenham relação com o público adulto, somente dessa forma o texto fará sentido para o leitor e ampliará os horizontes para formação de leitores. De acordo com os resultados da pesquisa nenhum dos dois cursos de Pedagogia analisados cumprem a tarefa de formar professores leitores, entre os motivos citados estão a falta de prática de leitura dos graduandos, futuros pedagogos, a reduzida carga horária do curso para as disciplinas voltadas para a formação do leitor e também para a inexistência de uma práxis docente que busque modificar a realidade negativa em relação à formação de leitores.

Em todas as pesquisas, verificou-se a importância de uma formação leitora para os professores, demonstrando que para despertar o gosto e o prazer da leitura é imperativo que o professor possua um certo repertório cultural e de leitura desenvolvido em sua vida, o que o que envolve o constante desenvolvimento de sua condição de leitor, principalmente a partir vivência cotidiana da prática da leitura. Portanto, a aproximação entre o professor e a atividade de leitura por prazer e fruição mostra-se essencial na tarefa de formar leitores, já que para que formar o aluno leitor é antes de mais nada pensar na formação do professor leitor.

\section{Conclusão}

O presente artigo teve como objetivo realizar uma reflexão sobre a importância da Leitura Deleite na formação do Professor Leitor, subsidiando essa perspectiva com trabalhos que apontam para a importância da leitura na formação docente. Caracterizada por proporcionar momentos de prazer e fruição da leitura além de oferecer ao leitor uma forma de ampliação de saberes e o contato com diversos textos, entende-se que essa a Leitura Deleite pode contribuir de forma positiva para a formação leitora do professor, visto que possibilita uma maior aproximação entre o professor e a leitura literária.

A leitura literária é uma prática cultural de natureza artística, se caracteriza por sua capacidade de promover uma forma de experiência estética passível de mobilizar sensações e conexões de sentidos, favorecendo a apreciação da obra literária de forma integral, esse tipo de leitura tem a potencialidade de colaborar com a formação humana do professor, assim como viabilizar outros conhecimentos que transpõem às questões que envolvem a inteligência e o raciocínio, mas mobilizem outros saberes da ordem do sensível. Justamente, por ser uma manifestação artística, a Leitura Deleite atua na percepção estética e possibilita uma maior aproximação entre o intelecto e a sensibilidade, favorecendo construção de conhecimentos e experiências em todos os contextos da vida do ser humano. Essa atividade não precisa se 
condicionar ao espaço escolar, podendo se tornar presença constante no cotidiano não só dos alunos, como também dos professores.

Logo, de acordo com a corrente de teóricos da educação na qual foi embasado esse trabalho, percebe-se a importância de eleger um projeto educacional voltado para valorização da aproximação entre o indivíduo e a realidade na qual está inserido, priorizando uma maior aproximação entre as dimensões pessoais e profissionais, reconhecendo que a dimensão sensível humana também é uma forma de saber que deveria ser incorporada, integrada aos saberes docentes e por conseguinte, deve ser apreciada por seus valores estéticos e artísticos, visto que a Literatura pode formar, porém não é um simples instrumento pedagógico ou educacional: "Ela não corrompe nem edifica, portanto, mas, trazendo livremente em si o que chamamos o bem e o mal, humaniza no sentido profundo, porque faz viver" (CANDIDO, 1972, p. 805).

\section{Referências}

ARAGÃO, Keila Gabryelle Leal. Sujeitos professores, sujeitos leitores: historias e práticas de leitura. Biblioteca Digital Brasileira de Teses e Dissertações, 2014. Disponível em: http://bdtd.ibict.br/ Acesso em: 11 jun. 2016.

ASBAHR, Melissa Cristina Correa. Os professores leitores dos livros de auto-ajuda para crianças. Biblioteca Digital Brasileira de Teses e Dissertações, 2005. Disponível em: <http://bdtd.ibict.br/>. Acesso em: 11 jun. 2016.

ALVES, Rubem. Educação dos Sentidos e mais... .Campinas: Verus Editora, 2005.

BASTOS, Regiane Pradela da Silva. Práticas de Alfabetizadoras em Formação pelo PNAIC: Estudo do Uso dos Acervos de Leitura. Plataforma Sucupira, 2016. Disponível em: https://sucupira.capes.gov.br/ Acesso em: 05 jun. 2017

BRASIL. Pacto Nacional pela Alfabetização na Idade Certa: formação de professores no Pacto Nacional pela Alfabetização na Idade Certa. Ministério da Educação, Secretaria de Educação Básica, Diretoria de Apoio à Gestão Educacional. Brasília: MEC, SEB, 2012.

BRASIL. Parâmetros curriculares nacionais: Língua Portuguesa. Língua portuguesa : Ensino de primeira à quarta série. Ministério da Educação. Secretaria de Educação Fundamental. Brasília: 2007.

CALDEIRA, Evandro Weigert. Perfil do professor-leitor de poesia: experiências de leitura de professores de Santa Maria - RS. Biblioteca Digital Brasileira de Teses e Dissertações, 2008. Disponível em: http://bdtd.ibict.br/ Acesso em: 11 jun. 2016.

CANDIDO, Antonio. A literatura e a formação do homem. São Paulo, Humanitas, 1972. Textos de intervenção. São Paulo: Duas cidades, 2002. 
DUARTE JÚNIOR, João-Francisco. O Sentido dos Sentidos: a educação (do) sensível.

Biblioteca Digital da Unicampi, 2000. Disponível em: <http://www.bibliotecadigital.unicamp.br/document/?code=vtls000211363\&fd=y >Acesso em: 11 jun. 2016.

. A montanha e o videogame: escritos sobre educação - Campinas: S.P: Papirus. 2010.

FAILLA, Zoara. (Org.). Retratos da Leitura do Brasil 4. São Paulo: Imprensa Oficial do Estado de São Paulo/Instituto Pró-Livro, 2016. Disponível em: <http://prolivro.org.br/home/images/2016/RetratosDaLeitura2016_LIVRO_EM_PDF_FINAL _COM_CAPA.pdf $>$. Acesso em: 02 mar. 2017.

GAUTHIER, Clermont. Relação com o saber, formação de professores e globalização. Ijuí: UNIJUÍ, 1998. p. 332-402.

LOVATO, Regilaine Gava. O Pacto Nacional pela Alfabetização na Idade Certa (PNAIC/2013) e os Professores do Município de Castelo - Es. Plataforma Sucupira, 2016. Disponível em: <https://sucupira.capes.gov.br/>. Acesso em: 05 jun. 2017.

MORAIS, Elaine Maria da Cunha, Leituras de professores de Pedagogia de instituições particulares de ensino superior em Belo Horizonte e algumas implicações nas suas práticas docentes. Tese de doutorado em Educação, 2014. Universidade Federal de Minas Gerais.

NÓVOA, António. Os professores e a sua formação. Lisboa. Publicações Dom Quixote, 1992.

Diz-me como ensinas e dir-te-ei que és e vice-versa. In: FAZENDA, Ivani. A pesquisa em educação e as transformações do conhecimento. Campinas: Papirus, 1995.

Professores - Imagens do Futuro Presente, Educa, Lisboa, 2009. Disponível em: $\overline{<h t t p: / / w w w . s l i d e s h a r e . n e t / m z y l b / a n t o n i o-n o v o a-n o v o-l i v r o>. ~ A c e s s o ~ e m ~ 21 / 06 / 2017 . ~}$

PAULINO, Graça. Leitura Literária. Glossário Ceale: termos de alfabetização, leitura e escrita para educadores. Belo Horizonte: UFMG/Faculdade de Educação, 2014.

PAIVA, Aparecida; MACIEL, Francisca; COSSON, Rildo. (Coord.). Literatura: ensino fundamental. In: Coleção Explorando o Ensino; v. 20. Ministério da Educação. Secretaria de Educação Básica (SEB). Brasília, 2010.

PIMENTA, Selma Garrido. Saberes pedagógicos e atividade docente. 7 ed. São Paulo: Cortez, 2012 p. 15-38.

RAMALHO, Mara Lúcia. Um Análise do Processo de Constituição do Professor Leitor: Os Sentidos e Significados Produzidos. Biblioteca Digital Brasileira de Teses e Dissertações, 2006. Disponível em: http://bdtd.ibict.br/ Acesso em: 11 jun. 2016.

ROLDÃO, Maria do Céu. Função docente: natureza e construção do conhecimento profissional. Rev. Bras. Educ., Abr 2007, vol.12, n.34, p. 94-103. ISSN 1413-2478.

ROSA, Cristina M. Alfabetização Literária: bebês, leitores e livros fascinantes. In: ALBUQUERQUE, Simone; FELIPE, Jane; CORSO, Luciana. Para pensar a formação docente na educação infantil. (Aprovado e aguarda publicação)

SILVA, Antonio Carlos da. A Importância da construção de sentidos na formação do professor-leitor. Biblioteca Digital Brasileira de Teses e Dissertações, 2007. Disponível em: $<$ http://bdtd.ibict.br/> Acesso em: 11 jun. 2016. 
SILVA, Kátia Andrade Inez. A Leitura nos Cursos de Pedagogia: Implicações da Práxis Docente na Formação do Professor Leitor. Biblioteca Digital Brasileira de Teses e Dissertações, 2015. Disponível em: <http://bdtd.ibict.br/>. Acesso em: 11 jun. 2016.

TARDELLI, Gláucia Maria Piato. Historias de leitura: a formação do professor leitor. Biblioteca Digital Brasileira de Teses e Dissertações, 1997. Disponível em: <http://bdtd.ibict.br/>. Acesso em: 11 jun. 2016.

Histórias de leitura de professores: a convivência entre diferentes cânones de leitura. Biblioteca Digital Brasileira de Teses e Dissertações, 2003. Disponível em: <http://bdtd.ibict.br/>. Acesso em: 11 jun. 2016.

TARDIF, Maurice. Saberes docentes e formação profissional. 14.ed. Petrópolis: Vozes, 2012.

ZILBERMAN, Regina. A leitura na escola. In: ZILBERMAN, Regina. (Org). Leitura em crise na escola. Porto Alegre: Mercado Aberto, 1993.

A escola e a leitura da Literatura. In: ZILBERMAN, Regina; ROSING, Tania. Escola e Leitura: velha crise, novas alternativas. São Paulo: Global, 2009. 